\title{
Endoscope Device
}

National Cancer Institute

\section{Source}

National Cancer Institute. Endoscope Device. NCI Thesaurus. Code C49940.

A device consisting of a tube containing flexible optic fibers that may be inserted into a body opening to allow a doctor to examine hollow org ans inside the body. The result may be viewed on a video screen. It has diagnostic (e.g., biopsy) and therapeutic capabilities. 